\title{
Enalapril Maleate
}

National Cancer Institute

\section{Source}

National Cancer Institute. Enalapril Maleate. NCI Thesaurus. Code C468.

The maleate salt form of enalapril, a dicarbocyl-containing peptide and angiotensinconverting enzyme (ACE) inhibitor with antihypertensive activity. As a prodrug, enalapril is converted by de-esterification into its active form enalaprilat. Enalaprilat competitively binds to and inhibits ACE, thereby blocking the conversion of angiotensin I to ang iotensin II. This prevents the potent vasoconstrictive actions of angiotensin II and results in vasodilation. Enalapril also decreases angiotensin II-induced aldosterone secretion by the adrenal cortex, which leads to an increase in sodium excretion and subsequently increases water outflow. 